\title{
Duration of female parental care and their survival in the little auk Alle alle - are these two traits linked?
}

\author{
Katarzyna Wojczulanis-Jakubas ${ }^{1}$ (D) - Marina Jiménez-Muñoz ${ }^{2,3} \cdot$ Dariusz Jakubas $^{1} \cdot$ Dorota Kidawa $^{1} \cdot$ \\ Nina Karnovsky ${ }^{4} \cdot$ Diana Cole $^{2}$. Eleni Matechou ${ }^{2}$
}

Received: 2 January 2020 / Revised: 27 May 2020 / Accepted: 29 May 2020 / Published online: 12 June 2020

(C) The Author(s) 2020

\begin{abstract}
Desertion of offspring before its independence by one of the parents is observed in a number of avian species with bi-parental care but reasons for this strategy are not fully understood. This behaviour is particularly intriguing in species where bi-parental care is crucial to raise the brood successfully. Here, we focus on the little auk, Alle alle, a small seabird with intensive bi-parental care, where the female deserts the brood at the end of the chick rearing period. The little auk example is interesting as most hypotheses to explain desertion of the brood by females (e.g. "re-mating hypothesis", "body condition hypothesis") have been rejected for this species. Here, we analysed a possible relationship between the duration of female parental care over the chick and her chances to survive to the next breeding season. We performed the study in two breeding colonies on Spitsbergen with different foraging conditions - more favourable in Hornsund and less favourable in Magdalenefjorden. We predicted that in Hornsund females would stay for shorter periods of time with the brood and would have higher survival rates in comparison with birds from Magdalenefjorden. We found that indeed in less favourable conditions of Magdalenefjorden, females stay longer with the brood than in the more favourable conditions of Hornsund. Moreover, female survival was negatively affected by the length of stay in the brood. Nevertheless, duration of female parental care over the chick was not related to their parental efforts, earlier in the chick rearing period, and survival of males and females was similar. Thus, although females brood desertion and winter survival are linked, the relationship is not straightforward.
\end{abstract}

\section{Significance statement}

When bi-parental care is crucial to raise the brood successfully, one parent desertion raises the question of why this happens. We examined this issue in the little auk, a small seabird with females deserting the brood at the end of the chick rearing period. We hypothesised that females deserting the brood save residual energy and, in this way, increases their chance to survive to the next breeding season. We found that duration of female parental care depends on environmental conditions, with longer staying with the brood in less favourable conditions. As expected, female survival decreased with duration of their staying with the brood but it was not related to their parental efforts (i.e. number of chick feedings, duration of foraging flights). In addition, survival of males and females was similar. Thus, although little auk females brood desertion and winter survival are linked, the relationship is not straightforward.

Keywords Alle alle $\cdot$ Brood desertion $\cdot$ Dovekie $\cdot$ Parental-care $\cdot$ Sex differences $\cdot$ Winter survival

Communicated by C. R. Brown

Electronic supplementary material The online version of this article (https://doi.org/10.1007/s00265-020-02862-9) contains supplementary material, which is available to authorized users.

Katarzyna Wojczulanis-Jakubas biokwj@univ.gda.pl

1 Department of Vertebrate Ecology and Zoology, Faculty of Biology, University of Gdańsk, Wita Stwosza 59, Gdańsk 80-308, Poland
2 School of Mathematics, Statistics and Actuarial Science, University of Kent, Sibson Building, Canterbury CT2 7FS, UK

3 German Centre for Integrative Biodiversity Research (iDiv) Halle-Jena-Leipzig, Leipzig, Germany

4 Department of Biology, Pomona College, 175 West Sixth Street, Claremont, CA 91711, USA 


\section{Introduction}

Female brood desertion in avian species with bi-parental care remains poorly understood, mostly because since Trivers' (1972) influential paper, the evolution of mating systems has been considered through the lens of the necessity of male care. When bi-parental care is not essential to rear offspring, males are often selected to desert or at least to reduce effort invested into the current brood. Owing to higher reproductive potential (i.e. higher number and rate of gametes production), males may benefit more than females from mating with additional partners, i.e. "re-mating hypothesis" (Trivers 1972; Bennett and Owens 2002; Orians 2011). Nevertheless, in some species it is possible for the female to desert the brood, leaving the partner to continue the care (e.g. Griggio et al. 2005; Rossmanith et al. 2009; Morton et al. 2010; Korpimäki et al. 2011; Béziers and Roulin 2016).

Considering the re-mating hypothesis in a broader context, the brood is deserted by the sex with a higher chance to remate (Székely and Williams 1995; Szekely and Cuthill 2000). Although males are favoured by basic sex differences in reproductive potential, the chances for re-mating may be circumstance-dependent. For example, in the Kentish plover, Charadrius alexandrinus, much depends on the current operational sex ratio in the adult population, and since it is often male-biased, females have a higher chance for successful remating, and so they are the deserting sex (Blashine and Blomqvist 1999; Pilastro et al. 2001; Webb et al. 2002). Opportunity for re-mating, however, reduces with progress of the breeding season (Szekely and Cuthill 2000; Griggio 2015) and for single-brooded species is non-existent. Examining such species may actually help to understand the most basic conditions for brood desertion.

The little auk (dovekie), Alle alle, is an example of a species for which the re-mating hypothesis fails to explain female brood desertion. For this small seabird, bi-parental care is crucial to raise the single chick successfully (Kidawa et al. 2012), and only at the end of the nesting period females desert their broods. Male parents continue the care and accompany their fledgling in its first flight to sea (Harding et al. 2004; Wojczulanis-Jakubas and Jakubas 2012), where it is believed they stay with the young for several weeks (Stempniewicz 2001). Little auks breed exclusively in the High Arctic zone (Stempniewicz 2001), during a short, two month long nesting period (4 weeks of incubation, and 3-4 weeks of chick rearing). They have to exploit the narrow window of time of the Arctic summer and do that with great precision. Females start egg-laying a week after ambient temperature achieves a constant (above $0{ }^{\circ} \mathrm{C}$ ) level, and the fledging period terminates a week before ambient temperature drops again below $0{ }^{\circ} \mathrm{C}$ level (Moe et al. 2009). In these conditions, a second breeding attempt is impossible. Even re-nesting birds that lost their brood very early in the season, have chicks with lower body mass and survival rate compared to the chicks from nonreplacement broods (Jakubas and Wojczulanis-Jakubas 2013). Thus, little auk females deserting their brood do not benefit from re-mating.

Another hypothesis to explain brood desertion is that it is triggered by decline in a parent's body condition (Wojczulanis-Jakubas et al. 2012). Indeed, body condition of provisioning adults has been proven to affect decisions about brood desertion in other avian species (body condition hypothesis), and there are two forms of that relationship. The first is when the parent deserting the brood is in relatively good body condition, which favours re-mating (Barta et al. 2002; Bleeker et al. 2005). The second form is that the parent deserts the brood due to poor body condition, thus, leaving the brood secures its own survival (Gratto-Trevor 1991; Pierce 1997; Roskaft 2006). However, in little auks no evidence has been found to support the body condition hypothesis in either form. First, parental effort of males and females is similar, if not male-biased (Harding et al. 2004; Welcker et al. 2009b; Wojczulanis-Jakubas et al. 2009, 2014a), which partly eliminates a potential reason for the expected poorer body condition of females. Secondly, the body condition of females has been analysed in detail, and their size-adjusted body mass, haematological parameters, and stress hormones have all been found to be similar to those of males (Wojczulanis-Jakubas et al. 2012, 2014a, b, 2015). Moreover, body condition of females is not considerably worse at the end of the chickrearing period compared to earlier stages of breeding (Wojczulanis-Jakubas et al. 2012). Even potentially costly egg production by the female (the egg mass constitutes $20 \%$ of female body mass; Stempniewicz 2001), seems to be compensated early in the season (Jakubas et al. 2008; Wojczulanis-Jakubas et al. 2014b). However, even if females do less than males, and even if their body condition is quite good at the end of the chick rearing period (and similar to that of males), it is still possible they are more prone than males to costs of breeding, and so may pay for those costs during the wintering period (Wojczulanis-Jakubas and Jakubas 2012). This sex-dependent cost of breeding may be related to basic sex differences in anatomy and physiology (i.e. females are slightly smaller and have a different hormonal balance). Thus, female little auks could desert their broods to secure their own future survival (as suggested for semipalmated sandpipers, Calidris pusilla, Gratto-Trevor 1991). The male partner might also benefit from female desertion, as the next season pair members are very likely to breed together (Stempniewicz 2001).

Thus, in this study we examined a possible relationship between the duration of female parental care over the chick and her wintering survival. For that purpose we analysed the duration of parental care over the chick in regard to adult wintering survival at two colonies, Hornsund and Magdalenefjorden (Spitsbergen, Norway). The two colonies 
located along the West coast of Spitsbergen, ca $300 \mathrm{~km}$ apart, differ in terms of environmental conditions in the little auk foraging areas (Jakubas et al. 2011). In Hornsund, the birds forage in the shelf area, which is primarily influenced by cold water masses, abundant in energy rich, Arctic zooplankton. In Magdalenefjorden area the shelf is more influenced by warm water masses, which are dominated by smaller, less caloric, Atlantic zooplankton (Kwasniewski et al. 2010). The intercolony differences in foraging conditions have the potential to differentiate birds' parental effort (Karnovsky et al. 2010, 2011; Hovinen et al. 2014b; Kidawa et al. 2015; Amélineau et al. 2016), which, in turn, may affect duration of parental care and/or adult survival. Although, in an evolutionary sense, long-lived species, such as the little auk, are predicted to prioritize self-maintenance and thus survival, at the cost of current reproduction (Beaulieu et al. 2011; Ghalambor and Martin 2016), parents may increase their parental investment in the short term when it is necessary, to secure the current breeding attempt. A study on little auk parents with experimentally increased flight costs during the chick-rearing period revealed that they are able to increase parental effort to some extent (Harding et al. 2009). Also, it has been revealed that artificially increased chick-begging intensity (by the exogenous corticosterone administration) induced a higher feeding frequency by little auk parents (Kidawa et al. 2017). An extension of parental effort, however, may affect parents' survival. Thus, we assumed that duration of female parental care in the little auk, even if related to the future survival of the female, is flexible. Indeed, the duration of parental care over the chick varies among females (Wojczulanis-Jakubas and Jakubas 2012) and seems to be different in Hornsund and Magdalenefjorden. Although it has not been examined deliberately in Hornsund, and this study is the first investigating it systematically, existing data suggest that females from that colony disappear earlier (a week before chicks fledge; Harding et al. 2004) than females from Magdalenefjorden, where the issue was analysed in detail ( $0-4$ days before chicks fledge; Wojczulanis-Jakubas and Jakubas 2012).

Examining in detail the duration of parental care over the chick provided by little auk females in the two colonies, we expected there would be inter-colony differences. We hypothesised that females from Hornsund, who invest in chick-rearing for a shorter amount of time, have higher wintering survival compared to females from Magdalenefjorden. As a control, we compared female vs male survival in the two colonies, expecting no sex differences in the colony with a more favourable foraging conditions in Hornsund, and higher survival of males than females in Magdalenefjorden colony with less favourable foraging conditions. Moreover, to further comprehend a triggering mechanism of brood desertion by little auk females, we examined the duration of female parental care over the chick in relation to the parental effort (foraging trip frequency and duration).

\section{Materials and methods}

\section{Study area}

The two breeding colonies in which we carried out the present study, Hornsund (SW Spitsbergen, $77^{\circ} 00^{\prime} \mathrm{N}, 15^{\circ} 33^{\prime} \mathrm{E}$ ) and Magdalenefjorden (NW Spitsbergen, $79^{\circ} 35^{\prime} \mathrm{N}, 11^{\circ} 05^{\prime} \mathrm{E}$ ), are both considered the biggest breeding aggregations of the little auk in Spitsbergen (Keslinka et al. 2019). Both colonies are under the influence of two currents - the Sørkapp Current which carries cold, less saline Arctic water, and the West Spitsbergen Current (an extension of the Norwegian Atlantic Current), which transports warmer, more saline Atlantic water (Cottier et al. 2005; Piechura and Walczowski 2009). However, due to an oceanographic system of the water masses, the range of the two currents are different for the two colonies. The Hornsund area is primarily under influence of the cold water current, while Magdalenefjorden area is dominated by the warm one (Tuomo and Harald 2001; Walczowski and Piechura 2007) (Fig. S1). Thus, the birds from Hornsund utilize mainly cold water masses with energy-rich prey within the shelf area $(8-93 \mathrm{~km}$ from the colony; Karnovsky et al. 2003; Jakubas et al. 2013, 2014), while those from Magdalenefjorden forage in less profitable warm water masses (Kwasniewski et al. 2010). Besides, birds from Magdalenefjorden also utilize more distant but profitable foraging areas, at the edge of the sea ice $(150 \mathrm{~km}$ from the colony; Jakubas et al. 2012, 2013). Consequently, to meet chick energy requirements, birds from Magdalenefjorden (compared to those from Hornsund), tend to perform fewer chick feedings and make longer foraging trips [in terms of the distance (Jakubas et al. 2013) but not necessarily in terms of time (Kidawa et al. 2015; see also a comparison of study seasons in the supplementary materials)].

\section{Fieldwork}

It was not possible to record data blind because our study involved focal animals in the field, nevertheless the sex of birds during the observations was known and the person (KWJ) performing molecular sexing was oblivious of birds identity.

To examine food provisioning and/or duration of parental care of little auk males and females, we performed direct 24 $48 \mathrm{~h}$ continuous observations in the two colonies (Hornsund and Magdalenefjorden; for more details about the observations see Wojczulanis-Jakubas and Jakubas 2012) and/or continuous $48 \mathrm{~h}$ video recording (Hornsund) of individually marked individuals (Table 1; the mode of registering birds behaviour was related to logistics). For that purpose, $c a$ two weeks before the onset of the first observation/recording session in a given season, we marked both breeding partners at focal nests using the system of plastic rings on legs and marks 
Table 1 Schedule, sample size and duration for the direct observations and video recordings. Number of nests in brackets indicate the same nest being monitored for the two stages of the chick rearing period in given season

\begin{tabular}{|c|c|c|c|c|c|}
\hline Site & Season & $\begin{array}{l}\text { Stage of chick rearing (chicks age in } \\
\text { days: mean/range) }\end{array}$ & $\begin{array}{l}\text { Number of } \\
\text { nests }\end{array}$ & Duration & Method \\
\hline \multirow[t]{4}{*}{ Magdalenefjorden } & 2009 & mid (mean $10 \mathrm{~d}$ ) & 12 & $48 \mathrm{~h}$ & observation \\
\hline & & late $(16-25 d)$ & (12) & $24 \mathrm{~h}$ & observation \\
\hline & 2010 & mid (mean $12 \mathrm{~d}$ ) & 26 & $48 \mathrm{~h}$ & observation \\
\hline & & late $(16-25 d)$ & (26) & $48 \mathrm{~h}$ & observation \\
\hline \multirow[t]{4}{*}{ Hornsund } & 2004 & late (starting from $14 \mathrm{~d}$ ) & 12 & $>48 \mathrm{~h}$ & video \\
\hline & 2016 & $\operatorname{mid}(11 \mathrm{~d})$ & 17 & $48 \mathrm{~h}$ & observation \\
\hline & & late (starting from $20 \mathrm{~d}$ ) & (17) & $>24 \mathrm{~h}$ & video \\
\hline & 2017 & $\begin{array}{l}\text { mid (13-14 d) } \\
\text { late (starting from } 20 \mathrm{~d})\end{array}$ & $\begin{array}{l}8 \\
(8)\end{array}$ & $\begin{array}{l}48 \mathrm{~h} \\
>48 \mathrm{~h}\end{array}$ & video \\
\hline
\end{tabular}

painted on the breast feathers, both of unique colour combinations (see Table 1 for details on sample sizes). This marking system allowed us to reliably recognize an individual if present in the nest site area. All these birds were also registered in a capture-recapture database (see details below).

We followed all the focal nests for hatching and fledging by daily inspection of the nest content starting a week before the expected time of hatching and fledging. Thus, we knew the age of the chicks in all the nests with 1-day precision. In all the nests we followed the male partner if he continued the care after the female desertion and recorded whether the chick fledged successfully.

During observations, we continuously observed focal individuals and noted their presence in the colony every $10 \mathrm{~min}$. We recorded all events of chick-feeding [bird appears after a period of absence in the colony, and enters the nest with a gular pouch filled with food; see more details on the observation routine in (Wojczulanis-Jakubas and Jakubas 2012; Grissot et al. 2019)]. For automatic recording of colony attendance of birds and chick feeding frequency, we set video cameras (four types, commercial HD models, with 1-s time lapse mode) at each focal nest. The camera recorded a $3 \mathrm{~m}$ radius of the focal nest entrance continuously for $\geq 48 \mathrm{~h}$. We manually screened the video material in search of marked individuals using VLC software (VideoLAN, France). As for the direct observations, we noted the birds' presence/ absence and feeding frequency but with 1-s precision.

To analyse little auk survival, we used capture-recapture data collected in seasons 2001-2017 in Hornsund and 2007-

Table 2 The three top models with $\Delta$ AIC $<2$ for the full data set (see Table S3 for a ranking of all the fitted models)

\begin{tabular}{llll}
\hline Data set & Model & No. parameters & $\Delta$ AIC \\
\hline Full & $\phi_{\text {site }}, p_{\text {site }}$ & 4 & 0.00 \\
Full & $\phi_{\text {site }}, p_{\text {sex, }}$ site & 5 & 1.29 \\
Full & $\phi_{\text {sex, site, }} p_{\text {site }}$ & 5 & 1.99 \\
\hline
\end{tabular}

2011 in Magdalenefjorden. The birds considered in the present study were captured by hand while incubating and/or brooding in nests. We considered only nests for which we could identity both members of the pair. We ringed each new capture with a unique number (Stavanger, Norway) and we took a small blood or feather sample for the purpose of molecular sexing (following the methods described in Jakubas and Wojczulanis 2007). In total, we considered in the analysis 737 birds from Hornsund, and 269 from Magdalenefjorden (for details see Tables S1, S2).

\section{Data analysis}

Data sources. Data on Hornsund female brood desertion are analysed here for the first time, while descriptive data on the duration of female parental care in Magdalenefjorden have already been presented in Wojczulanis-Jakubas and Jakubas 2012. Here, data from Magdalenefjorden are used in comparison with Hornsund.

Duration of female parental care over the chick. Since the exact day of colony departure was not known for all the females (for some females there was 1-4 days gap between the last observation and the first day of confirmed absence; see Fig. 1 mid panel for exact number of these females for each colony) we treated these records as censored data (i.e. unknown exact time of female desertion) in the Cox model (Fig. 1 bottom panel). For all the analyses, where we considered duration of female parental care over the chick, we averaged the last observation of the female and the first day of her confirmed absence, and we refer to this as the estimated duration of female parental care over the chick (also estimated chick age at the female desertion).

In Hornsund, we collected data on the duration of female parental care for three seasons $(2004,2016,2017)$, and in Magdalenefjorden for two seasons (2009 and 2010) (Table 1). There were inter-seasonal differences in the duration of female parental care (but not in duration of the nesting period) in the Hornsund colony, where the period of chick 
Fig. 1 Probability of female brood desertion (upper panel), number of females observed in the colony (middle panel), and number of censored data (i.e. as uncompleted associated with lower weight in the analysis; bottom panel) at successive days of chick's life in Hornsund (blue) and Magdalenefjorden colony (orange)
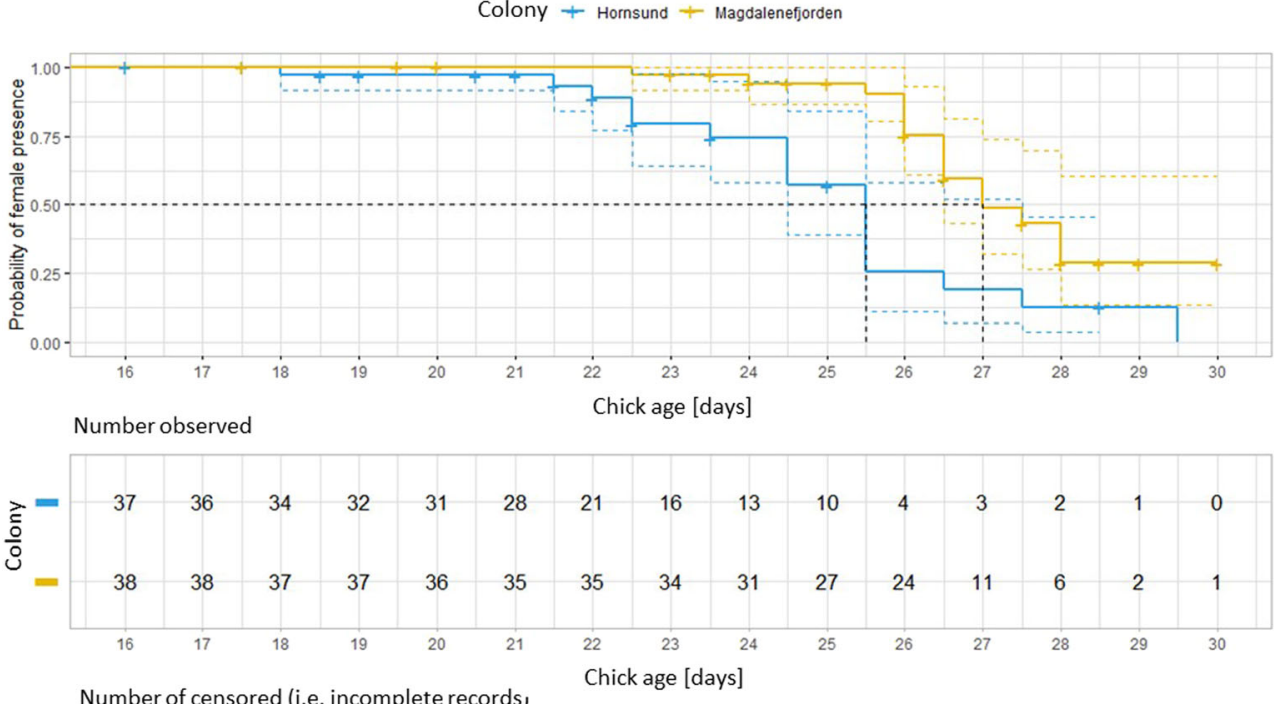

Number of censored (i.e. incomplete records,

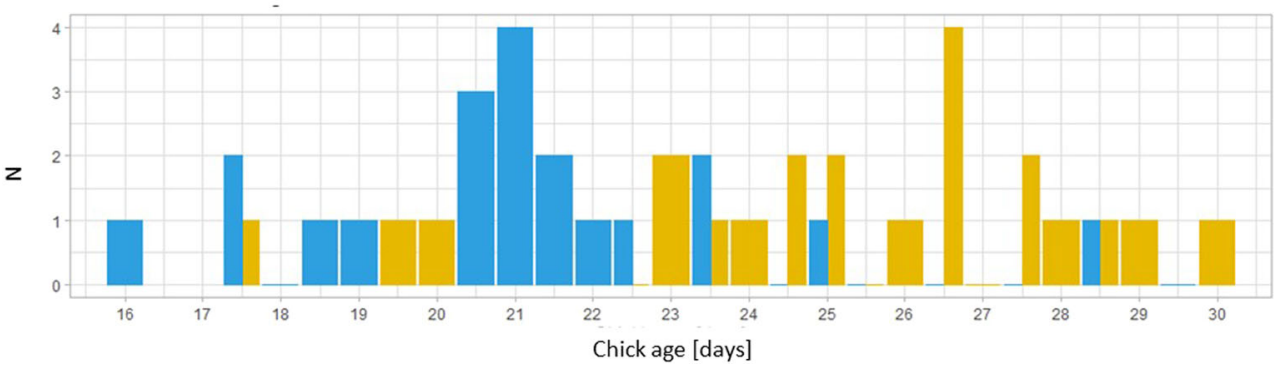

rearing by females increased over the years. For Magdalenefjorden we did not observe such differences (Fig. S3, S4). This inter-seasonal difference in the Hornsund colony may be an effect of inter-annual fluctuations in foraging conditions but it is also possible that ongoing climate change are having an effect. If female brood desertion is a flexible trait that is related to environmental conditions, as we advocate in the present study, deteriorating environmental conditions in the Hornsund area (indeed the annual influx of warm water masses in Hornsund is greater at present than was observed a decade ago; Promińska et al. 2017) might explain the longer duration of female parental care. Nevertheless, for the purposes of the present study, we pooled data from all the seasons for each colony so we could compare various traits between the two colonies without the loss of degrees of freedom.

To compare duration of female parental care between the two colonies we fitted a Cox proportional hazards regression model using survminer (Kassambara et al. 2018) and survival (Therneau and Lumley 2019) packages in R software (R Core Team 2018). We tested this relationship with a likelihood ratio test (LRT) and considered it significant at $p$ value of $<0.05$. Since inter-colony differences in duration of female parental care may be related to intercolony differences in duration of the nesting period, we also compared the duration of nesting period between the two colonies. To do so, we performed a permutation test, randomizing the duration of nesting period between the colonies, calculating the inter-colony difference and then comparing it with the observed one in total of 1000 iterations. If the observed difference in duration of the nesting period between the two colonies was within the central 95\% differences obtained in the randomisation procedure, then we considered it statistically insignificant.

Survival. To analyse winter survival of adult males and females from the two colonies (capture-recapture data), we used the Cormack-Jolly-Seber model (CJS) (see, for example, McCrea and Morgan 2014), which provides estimates of annual survival $(\phi)$ whilst accounting for imperfect detection (capture probability $p$ ). We fitted models with all possible combinations of site and sex covariates in the survival $\phi$ and capture parameter $p$. We compared the models using an information-theoretic approach, with AIC as the chosen criterion (Zuur et al. 2009), with $\triangle \mathrm{AIC}=\mathrm{AIC}-\min (\mathrm{AIC})$. We further considered only models with $\triangle \mathrm{AIC}<2$ (Burnham and Anderson 2002).

The differences in the number of years for each data set (Hornsund: 15, Magdalenefjorden: 5) did not affect the parameter estimates obtained from the capture-recapture model as we did not look at time-dependent results. To check our results, we also fitted the data sets separately (i.e. run the same models for each colony) and we found that the estimates were similar to the ones presented in results section. 
We also fitted models to the subset of capture-recapture data containing only records of females, for which we collected data of their duration of parental care (i.e. 56 females, with 25 from Hornsund, and 31 from Magdalenefjorden; hereafter the female subset). However, for these data the site and the duration of female parental care covariates were correlated. A solution to address this collinearity issue would be to fit a capture-recapture model in which survival was dependent on the duration of female parental care for each site separately. However, we were unable to do so for two reasons. First, we were unable to estimate capture probability for the female subset from Magdalenefjorden (the data did not contain zeroes between capture occasions). Second, when we fit the capturerecapture model for the Hornsund female subset the survival parameter estimates reached the boundaries. Because of all these limitations we included the data for the 56 females in our analysis but we did not consider site covariates, being aware of the possible effect of muliticolinearity (thus these results should be treated with caution). In this analysis, the survival probability depended on the presence covariate (i.e. estimated chick age at the female desertion) and the capture probability was constant. For significance, we established 95\% confidence intervals for the regression line with a bootstrap method. We performed all this survival modelling in $\mathrm{R}$ (R Core Team 2018).

Parental effort. To analyse the relationship between a female parental effort and her duration of parental care over the chick, we focused on the number of chick feedings performed by each female per $24 \mathrm{~h}$, and the duration of her foraging trips. For this analysis, we used data for only two of the three seasons for Hornsund, as we did not have data from the midchick rearing period in 2004. We calculated the number of feedings per $24 \mathrm{~h}$ from the $48 \mathrm{~h}$ unit of observation/recordings, counting the number of feedings in the whole unit performed by the female and dividing it by 2 . Since duration of foraging trips in the little auk has a bimodal distribution (Steen et al. 2007; Welcker et al. 2009a; Wojczulanis-Jakubas et al. 2010; Brown et al. 2012) we established division for short- and longlasting trips. As the distribution of duration of foraging trips may be season- or site- dependent (Welcker et al. 2009a), initially we established the cut-off value for each season/ colony separately, based on the algorithm proposed by Welcker et al. (2009a), where the best cut-off value is that which minimizes the sum of the variances of both trip types given their log-normal distribution. It resulted in four different cut-off values: $7.5 \mathrm{~h}$ (Hornsund 2016), $7.9 \mathrm{~h}$ (Hornsund 2017), $6.6 \mathrm{~h}$ (Magdalenefjorden 2009), and $7.3 \mathrm{~h}$ (Magdalenefjorden 2010) (Fig. S2). However, these cut-off values did not differ remarkably, therefore, we also considered a single cut-off value for the whole data set (set on $8.8 \mathrm{~h}$ ) following WojczulanisJakubas et al. (2010). This single cut-off value is based on the assumption that the long trips performed during the chickrearing period serve primarily the adults' self-maintenance (although the birds bring food for the chick from long trips too), and so they should last as long as the foraging trips performed by adults during the incubation period, when the birds are free of chick provisioning duty (WojczulanisJakubas et al. 2010). Since, both approaches to trips split gave qualitatively the same results in the analysis of the relationship between the duration of foraging trips of a female and her duration of parental care over the chick, for simplicity we finally presented results based on the single cut-off value split.

We analysed the estimated duration of female parental care over the chick using linear regression (linear model; LM), with the number of chick-feedings and colony as explanatory variables. We also included in the model the interaction between the colony and the number of feeds by females, so we could model differences on the effect of feeding rates on the estimated duration of female parental care between the sites. Then, we analysed the relationship between the estimated duration of female parental care and the duration of foraging trips for females, using linear mixed models, separately for each trip type. We regressed the duration of female parental care with duration of the trip and the colony as explanatory variables. To control for a possible effect of pseudoreplication (multiple foraging trips performed by each female), we included female identity in the model as a random factor. The interaction between the colony and the mean duration of trips was also included in the model, so we could model differences on the effect of the mean duration of the trip on the estimated duration of female parental care over the chick among both sites. We checked assumptions of all the models using visual inspection of the residuals.

We performed all the analysis in $\mathrm{R}$ environment ( $\mathrm{R}$ Core Team 2018), using ggplot2 (Wickham et al. 2018) and ggpubr (Kassambara 2018) packages for plotting.

\section{Results}

Duration of female parental care. Overall, females deserted their chick when it was between 16 and 30 days old. On average, females in Hornsund deserted the brood three days earlier than females from Magdalenefjorden. The mean estimated chick age at the female desertion was $22.6(\mathrm{SE} \pm 0.52)$ in Hornsund and 25.6 ( $\mathrm{SE} \pm 0.42)$ in Magdalenefjorden. Even considering that some data were censored (i.e. being uncompleted had a different weight in the analysis), the inter-colony difference held true (LRT $=10.36, p<0.001$; Fig. 1). In both colonies, chicks fledged on average on 26 day of life (Hornsund: $\mathrm{SE}=0.37$, Magdalenefjorden: $\mathrm{SE}=0.31$; Fig. 2, and Fig. S4 for values separate for seasons). This difference in chicks age at the moment of female brood desertion resulted in proportionally longer periods of male-only care in Hornsund. Consistently, as female little auks stayed longer with the brood 
Fig. 2 Density distribution of the duration of nesting period (i.e. chicks age at fledging) in Hornsund and Magdalenefjorden colony (left panel), and bootstrap distribution of the inter-colony difference in mean day of the chicks fledging (right panel); the black vertical line at 0 , being within the range of the permutated distribution, indicates no significant difference between the two colonies in the duration of the nesting period

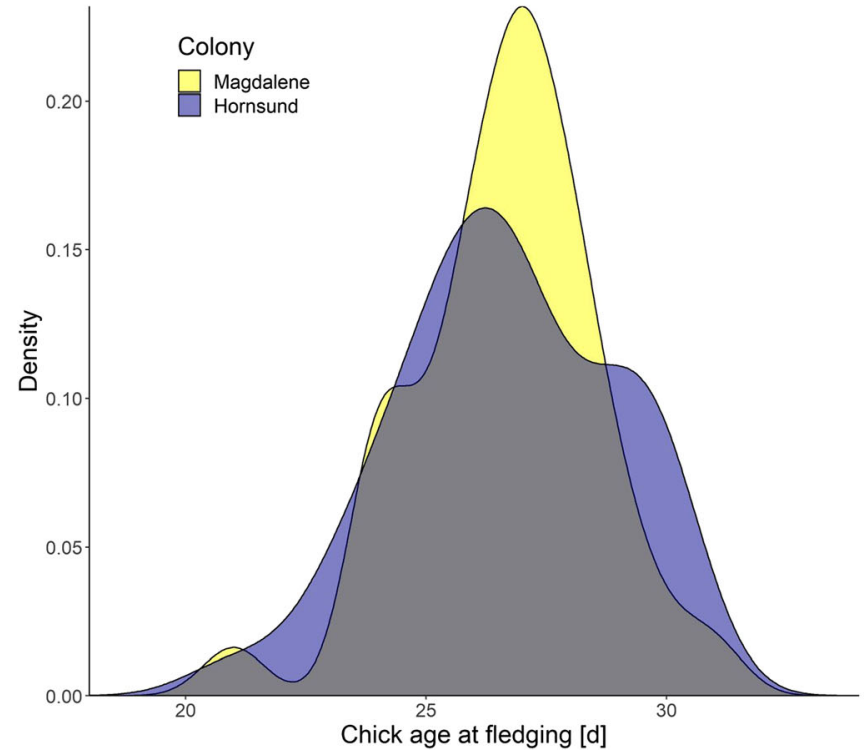

in Magdalenefjorden, some of Magdalenefjorden chicks did not experience uni-parental care.

Survival. We first considered the capture-recapture data for all individuals. We fitted all the possible models, which included all combinations in terms of site and sex covariates in the survival $(\phi)$ and the capture probability $(p)$. The three best models in terms of AIC (Table 2; further results are given in the supplementary material in Table S3) included site and sex dependencies in both parameters. For the best model, both survival and capture probabilities depended on the site covariate. The survival probability for this model was estimated higher in Hornsund $(\phi=0.75, \mathrm{SE}=0.07)$ than in Magdalenefjorden $(\phi=0.44, \mathrm{SE}=0.10)$. In contrast, the capture probability was estimated lower in Hornsund ( $p=0.34$, $\mathrm{SE}=0.07)$ than in Magdalenefjorden $(p=0.76, \mathrm{SE}=0.25)$. In the second best model, survival again only depended on the site covariate, and for this parameter the estimates were identical to those in the top model. On the other hand, in the second best model, the capture probability depended both on the sex and site covariates, and the corresponding capture probabilities were $p=0.33(\mathrm{SE}=0.10)$ for females in Hornsund and $p=$ $0.35(\mathrm{SE}=0.10)$ for males in Hornsund; $p=0.75(\mathrm{SE}=0.26)$ for females in Magdalenefjorden and $p=0.77(\mathrm{SE}=0.26)$ for males in the same site. In the third best model the survival probability depended on both covariates, and the capture probability depended only on the site covariate. In this model the survival probabilities were $\phi=0.75(\mathrm{SE}=0.09)$ for both females and males in Hornsund, and $\phi=0.43(\mathrm{SE}=0.11)$ for females in Magdalenefjorden and $\phi=0.44(\mathrm{SE}=0.12)$ for males in the same site. The capture probabilities were similar to those in the best model. These results show that the probability of survival was much higher in Hornsund than in Magdalenefjorden, however the capture probability was much lower in Hornsund. The estimates obtained in the second and third best models in terms of AIC suggest that survival and capture probabilities were similar for both sexes.

Considering the female subset data (with both colonies pooled) we found a negative trend in the relationship between the duration of female parental care over the chick and their survival, $\left(\alpha=1.20\right.$ (0.19), $\beta_{\text {presence }}=-0.25$ (0.19), where alpha and beta are the intercept and slope respectively corresponding to the logit transformed survival probability; Fig. 3).

Parental effort. There was no apparent relationship between duration of female parental care over the chick and the number of chick-feedings or the duration of short or long foraging trips performed in the mid-chick rearing period (Table 3; Fig. S5, S6).

\section{Discussion}

As expected, we found little auk females from Hornsund departed the colony on average 3 days earlier that those from Magdalenefjorden. Since duration of nesting period was similar in the two colonies, this difference indicated proportionally longer parental investment of females in the Magdalenefjorden colony. The two colonies differ in terms of environmental conditions in the little auk foraging areas, with Hornsund having usually more favourable conditions (see, for example, Jakubas et al. 2011; Kidawa et al. 2015). Thus, the inter-colony difference in the duration of female parental care over the chick seems to be related to these conditions, rather than a feature of the colony. The inter-seasonal difference in the duration of female parental care over the chick in Hornsund (Fig. S3) seems to support this conclusion. Thus, female little auks stay with the brood longer in less favourable conditions, probably in this way compensating for food shortages. In other words, they stay with the brood 
Fig. 3 Estimated survival probability for both sites as a function of the estimated duration of female parental care over the chick (expressed as estimated chick age at the female desertion). The $95 \%$ bootstrapped confidence interval is shown by the dashed lines

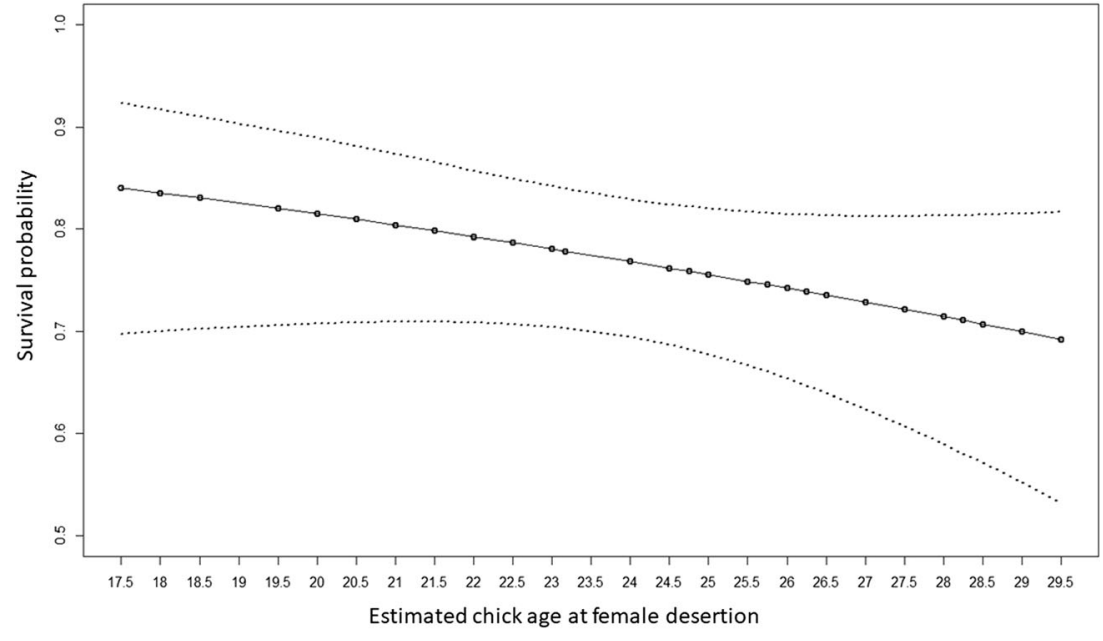

as long as it is necessary. Adjustment of parental behaviour by female little auks to current environmental conditions is consistent with the great flexibility of the species observed in various contexts related to foraging (Jakubas et al. 2011, 2016, 2020; Brown et al. 2012; Gremillet et al. 2012; Amélineau et al. 2016).

Although female brood desertion as a response to environmental condition, being a background question of the present study, seems to be the most parsimonious explanation of the overall variation in the duration of little auk female parental care over the chick, we cannot also exclude another factor also influencing female behaviour. In Magdalenefjorden as well as in Hornsund there are both early- and late-deserting females. An alternative (or additional) explanation to the observed variation could be a variation coordination within pairs of parental responsibilities. It has been found that degree of parental

Table 3 Output of models describing association between estimated time of colony departure of females and colony/ $\mathrm{N}$ feedings/short trips/ long trips/interactions. $\mathrm{N}$ feedings - number of the chick feedings performed by female per $24 \mathrm{~h}, \mathrm{LT}$ - long foraging trips, ST - short trips

\begin{tabular}{lrrrc}
\hline Model/Parameter & Estimate & \multicolumn{1}{l}{ SE } & \multicolumn{1}{l}{$\mathrm{t}$} & $p$ \\
\hline LM; Intercept & 24.38 & 2.13 & 11.47 & $<0.001$ \\
N feedings & -0.15 & 0.51 & -0.29 & 0.78 \\
$\quad$ Colony & 0.06 & 2.70 & 0.02 & 0.98 \\
$\quad$ Colony x N feedings & 0.39 & 0.63 & 0.61 & 0.55 \\
LMM; Intercept & 23.73 & 0.58 & 40.66 & $<0.001$ \\
Short trips (ST) duration & -0.03 & 0.06 & -0.46 & 0.65 \\
$\quad$ Colony (M) & 1.57 & 0.79 & 1.98 & 0.06 \\
Colony (M) x ST duration & 0.01 & 0.07 & 0.20 & 0.84 \\
LMM; Intercept & 24.38 & 2.07 & 11.79 & $<0.001$ \\
Long trips (LT) duration & -0.04 & 0.13 & -0.34 & 0.74 \\
$\quad$ Colony (M) & -0.13 & 2.59 & -0.05 & 0.96 \\
Colony (M) x LT duration & 0.11 & 0.16 & 0.71 & 0.48 \\
\hline
\end{tabular}

coordination is strongly associated with the ultimate consequence of sexual conflict such as brood desertion, with low coordination with mates resulting in earlier brood desertion of one parent (Baldan and Griggio 2019). A recent study on little auk parental strategies has showed that parents do coordinate their chick provisioning, avoiding overlapping of long foraging trips in regard to each other (i.e. securing even in time food delivery; Wojczulanis-Jakubas et al. 2018). Parental coordination has been found to be highly variable and could not be explained by environmental conditions (Grissot et al. 2019). In such a context, female brood desertion in the little auk could be linked to low coordination. We are not currently able to test for such a possibility but this issue definitely warrants a thorough study.

Although long-lived species are not expected to prioritize offspring care at the cost of their own survival (Beaulieu et al. 2011; Ghalambor and Martin 2016), in the short term they could extend their parental investment in order to ensure that the current breeding attempt is successful. In this context, we expected that female little auks from Magdalenefjorden colony would extend their parental care to secure the current breeding attempt and that could further influence their winter survival. We found that, indeed, the relationship between survival probability and estimated duration of female parental care over the chick was negative - the longer the female stayed with the brood the lower was the probability of her survival. However, due to data limitations explained above, we were unable to obtain any site-specific results. Therefore, to confirm this relationship, future work should focus on the collection of additional data for several more seasons. Besides, the duration of female parental care over the chick was not related to their parental effort earlier in the chick rearing period, and survival of males and females was similar both in Hornsund and Magdalenefjorden colony. Thus, although female brood desertion and winter survival are linked, the relationship is not that straightforward. 
Survival of birds from Magdalenefjorden was in general lower compared to Hornsund. This difference is likely to be related to the difference in environmental conditions between the two colonies (Jakubas et al. 2011; Hovinen et al. 2014a; Kidawa et al. 2015). Although both colonies experience interannual differences in environmental conditions, overall, parental birds in Magdalenefjorden work harder than those in Hornsund. The difference in effort is shown by more distant and sometimes also longer duration of foraging flights in the former colony (Jakubas et al. 2011, 2013; Kidawa et al. 2015; our results on difference in the duration of short foraging trips also support the conclusion). Thus, birds from Magdalenefjorden seem to pay a cost of breeding in less favourable foraging conditions in terms of their lower winter survival. Obviously, this may not be the only explanation for the inter-colony differences in the adult survival. We cannot exclude that, for instance, the difference is generated at the wintering grounds. Hovinen et al. (2014) have reported that annual survival rates of adult little auks breeding on Svalbard are influenced not only by summer sea surface temperatures (SST) but also winter values of the North Atlantic Oscillation (NAO) - an increase in both parameters is related to decreases in little auk survival. Although wintering areas of Magdalenefjorden population are yet undescribed, it is likely that birds from Hornsund utilize different wintering areas, given the high variability in the choice of wintering grounds described so far (Fort et al. 2013; P. Dufour et al. unpublished data). If so, birds from the two colonies might be exposed to different wintering conditions, which in turn might affect their survival.

Our results demonstrate that female brood desertion in the little auk is a flexible trait dependent on environmental conditions. However, although staying with the brood longer was negatively associated with their winter survival, the relationship was not that straightforward, as the duration of female parental care over the chick was not related to their parental efforts performed earlier in the chick rearing period, and survival of males and females was similar in both colonies despite distinct environmental conditions. These results all together suggest that little auk females rather do not jeopardize their survival by an extended parental care. Hence, the next step in examining the reasons why females desert the brood in the little auk should be perhaps reversing the question and making it male-oriented: why do males stay with their chicks longer than females?

Acknowledgments We thank Lech Iliszko, Kasia Pińska, Magda Hadwiczak, and Mateusz Barcikowski for their assistance in the field. We also express our gratitude to the anonymous reviewers whose comments helped to improve the manuscript.

Author contributions Concept of the study (KWJ, MJM, EM, DC), Data collection (KWJ, DJ, DK, NJK), Data analysis (MJM, KWJ, EM, DC), writing and editing manuscript (all authors).
Funding information Our study was supported by grants from Poland through the Polish Ministry of Science and Education (Juventus Plus 0470/P01/2010/70 and 2017/25/B/NZ8/01417), funds from University of Gdańsk, and from Norway through the Norwegian Financial Mechanism (ALKEKONGE, PNRF-234-AI-1/07).

Data availability Raw data will be made available upon reasonable request from the authors.

\section{Compliance with ethical standards}

Conflict of interest The authors declare that they have no conflict of interests.

Ethical approval All applicable international rules for the use of animals, as specified in the guideline of the Association for the Study of Animal Behaviour, were followed. Besides birds were handled under permission of the Norwegian Animal Research Authority and the Governor of Svalbard (2007/00150-9, 2007/00150-11, 17/00663-2, 17/00663-7).

Open Access This article is licensed under a Creative Commons Attribution 4.0 International License, which permits use, sharing, adaptation, distribution and reproduction in any medium or format, as long as you give appropriate credit to the original author(s) and the source, provide a link to the Creative Commons licence, and indicate if changes were made. The images or other third party material in this article are included in the article's Creative Commons licence, unless indicated otherwise in a credit line to the material. If material is not included in the article's Creative Commons licence and your intended use is not permitted by statutory regulation or exceeds the permitted use, you will need to obtain permission directly from the copyright holder. To view a copy of this licence, visit http://creativecommons.org/licenses/by/4.0/.

\section{References}

Amélineau F, Grémillet D, Bonnet D, Le Bot T, Fort F (2016) Where to forage in the absence of sea ice? Bathymetry as a key factor for an Arctic seabird. PLoS One 11:e0157764. https://doi.org/10.1371/ journal.pone. 0157764

Baldan D, Griggio M (2019) Pair coordination is related to later brood desertion in a provisioning songbird. Anim Behav 156:147-152. https://doi.org/10.1016/j.anbehav.2019.08.002

Barta Z, Houston AI, McNamara JM, Székely T (2002) Sexual conflict about parental care: the role of reserves. Am Nat 159:687-705. https://doi.org/10.1086/339995

Beaulieu M, Reichert S, Le Maho Y, Ancel A, Criscuolo F (2011) Oxidative status and telomere length in a long-lived bird facing a costly reproductive event. Funct Ecol 25:577-585. https://doi.org/ 10.1111/j.1365-2435.2010.01825.x

Bennett P, Owens I (2002) Evolutionary ecology of birds life histories, mating systems and extinction, 1st edn. Oxford University Press, Oxford

Béziers P, Roulin A (2016) Double brooding and offspring desertion in the barn owl Tyto alba. J Avian Biol 47:235-244. https://doi.org/10. 1111/jav.00800

Blashine S, Blomqvist D (1999) Parental behaviour in Kentish plovers: who cares? Trends Ecol Evol 14:293-294

Bleeker M, Kingma SA, Szentirmai I, Szekeley T, Komdeur J (2005) Body condition and clutch desertion in penduline tit Remiz 
pendulinus. Behaviour 142:1465-1478. https://doi.org/10.1163/ 156853905774831855

Brown ZW, Welcker J, Harding AMA, Walkusz W, Karnovsky N (2012) Divergent diving behavior during short and long trips of a bimodal forager, the little auk Alle alle. J Avian Biol 43:215-226. https://doi. org/10.1111/j.1600-048X.2012.05484.x

Burnham K, Anderson D (2002) Model selection and multimodel inference: a practical information-theoretic approach, 2nd edn. Springer, New York

Cottier F, Tverberg V, Inall M, Svendsen H, Nilsen F, Griffiths C (2005) Water mass modification in an Arctic fjord through cross-shelf exchange: the seasonal hydrography of Kongsfjorden, Svalbard. J Geophys Res Ocean 110:1-18. https://doi.org/10.1029/ 2004JC002757

Fort J, Moe B, Strøm H, Grémillet D, Welcker J, Schultner J, Jerstad K, Johansen KL, Phillips RA, Mosbech A (2013) Multicolony tracking reveals potential threats to little auks wintering in the North Atlantic from marine pollution and shrinking sea ice cover. Divers Distrib 19:1322-1332. https://doi.org/10.1111/ddi.12105

Ghalambor CK, Martin TE (2016) Fecundity-survival trade-offs and parental parental risk-taking in birds. Science 292:494-497

Gratto-Trevor CL (1991) Parental care in Semipalmated sandpipers Calidris pusilla: brood desertion by females. Ibis 133:394-399. https://doi.org/10.1111/j.1474-919X.1991.tb04587.x

Gremillet D, Welcker J, Karnovsky N, Walkusz W, Hall ME, Fort J, Brown ZW, Speakman J, Harding AMA (2012) Little auks buffer the impact of current Arctic climate change. Mar Ecol Prog Ser 454: 197-206. https://doi.org/10.3354/meps09590

Griggio M (2015) An experimental test on time constraint and sexual conflict over parental care. Ecol Evol 5:3622-3627. https://doi.org/ 10.1002/ece3.1620

Griggio M, Matessi G, Pilastro A (2005) Should I stay or should I go? Female brood desertion and male counterstrategy in rock sparrows. Behav Ecol 16:435-441. https://doi.org/10.1093/beheco/ari009

Grissot A, Araya-Salas M, Jakubas D, Kidawa D, Boehnke R, Błachowiak-Samołyk K, Wojczulanis-Jakubas K (2019) Parental coordination of chick provisioning in a planktivorous Arctic seabird under divergent conditions on foraging grounds. Front Ecol Evol 7. https://doi.org/10.3389/fevo.2019.00349

Harding AMA, Kitaysky AS, Hall ME, Welcker J, Karnovsky NJ, Talbot SL, Hamer KC, Gremillet D (2009) Flexibility in the parental effort of an Arctic-breeding seabird. Funct Ecol 23:348-358. https://doi. org/10.1111/j.1365-2435.2008.01488.x

Harding AMA, Van Pelt TI, Lifjeld JT, Mehlum F (2004) Sex differences in little auk Alle alle parental care: transition from biparental to paternal-only care. Ibis 146:642-651. https://doi.org/10.1111/j. 1474-919x.2004.00297.x

Hovinen JE, Welcker J, Descamps S, Strom H, Jerstad K, Berge J, Steen $\mathrm{H}$ (2014a) Climate warming decreases the survival of the little auk (Alle alle), a high Arctic avian predator. Ecol Evol 4:3127-3138. https://doi.org/10.1002/ece3.1160

Hovinen JEH, Wojczulanis-Jakubas K, Jakubas D, Hop H, Berge J, Kidawa D, Karnovsky NJ, Steen H (2014b) Fledging success of little auks in the high Arctic: do provisioning rates and the quality of foraging grounds matter? Polar Biol 37:665-674. https://doi.org/ 10.1007/s00300-014-1466-1

Jakubas D, Głuchowska M, Wojczulanis-Jakubas K, Karnovsky NJ, Keslinka L, Kidawa D, Walkusz W, Boehnke R, Cisek M, Kwasniewski S, Stempniewicz L (2011) Foraging effort does not influence body condition and stress level in little auks. Mar Ecol Prog Ser 432:277-290. https://doi.org/10.3354/meps09082

Jakubas D, Iliszko L, Wojczulanis-Jakubas K, Stempniewicz L (2012) Foraging by little auks in the distant marginal sea ice zone during the chick-rearing period. Polar Biol 35:73-81. https://doi.org/10.1007/ s00300-011-1034-X
Jakubas D, Trudnowska E, Wojczulanis-Jakubas K, Iliszko K, Kidawa D, Darecki M, Błachowiak-Samołyk K, Stempniewicz L (2013) Foraging closer to the colony leads to faster growth in little auks. Mar Ecol Prog Ser 489:263-278. https://doi.org/10.3354/ meps 10414

Jakubas D, Wojczulanis K (2007) Predicting the sex of dovekies by discriminant analysis. Waterbirds 30:92-96. https://doi.org/10. 1675/1524-4695(2007)030[0092:PTSODB]2.0.CO;2

Jakubas D, Wojczulanis-Jakubas K (2013) Rates and consequences of relaying in little auks Alle alle breeding in the high Arctic an experimental study with egg removal. J Avian Biol 44:62-68. https://doi. org/10.1111/j.1600-048X.2012.05790.x

Jakubas D, Wojczulanis-Jakubas K, Boehnke R, Kidawa D, BłachowiakSamołyk K, Stempniewicz L (2016) Intra-seasonal variation in zooplankton availability, chick diet and breeding performance of a high Arctic planktivorous seabird. Polar Biol 391:1547-1561. https://doi. org/10.1007/s00300-015-1880-z

Jakubas D, Wojczulanis-Jakubas K, Iliszko L, Darecki M, Stempniewicz L (2014) Foraging strategy of the little auk Alle alle throughout breeding season - switch from unimodal to bimodal pattern. J Avian Biol 45:551-560. https://doi.org/10.1111/jav.00303

Jakubas D, Wojczulanis-Jakubas K, Iliszko LM, Kidawa D (2020) Flexibility of little auks foraging in various oceanographic features in a changing Arctic. Sci Rep 10:8283. https://doi.org/10.1038/ s41598-020-65210-x

Jakubas D, Wojczulanis-Jakubas K, Kreft R (2008) Sex differences in body condition and hematological parameters in little auk Alle alle during the incubation period. Ornis Fenn 85:90-97

Karnovsky N, Harding A, Walkusz W, Kwasniewski S, Goszczko I, Wiktor J J, Routti H, Bailey A, McFadden L, Brown Z, Beaugrand G, Grémillet D (2010) Foraging distributions of little auks Alle alle across the Greenland Sea: implications of present and future Arctic climate change. Mar Ecol Prog Ser 415:283293. https://doi.org/10.3354/meps08749

Karnovsky NJ, Brown ZW, Welcker J, Harding AMA, Walkusz W, Cavalcanti A, Hardin A, Kitaysky AS, Gabrielsen GW, Gremillet D (2011) Inter-colony comparison of diving behavior of an Arctic top predator: implications for warming in the Greenland Sea. Mar Ecol Prog Ser 440:229-240. https://doi.org/10.3354/meps09351

Karnovsky NJ, Kwasniewski S, Weslawski JM, Walkusz W, Beszczyńska-Moller A (2003) Foraging behaviour of little auks in a heterogeneous environment. Mar Ecol Prog Ser 253:289-303

Kassambara A (2018) Package "ggpubr". 'ggplot2' based publication ready plots version, https://CRAN.R-project.org/ package $=$ ggpubr

Kassambara A, Kosinski M, Biecek P, Scheipl F (2018) Package' survminer '. Drawing survival curves using "ggplot2" version, https: //CRAN.R-project.org/package=survminer

Keslinka LK, Wojczulanis-Jakubas K, Jakubas D, Neubauer G (2019) Determinants of the little auk (Alle alle) breeding colony location and size in W and NW coast of Spitsbergen. PLoS One 14: 0212668. doi: https://doi.org/10.1371/journal.pone.0212668, e0212668

Kidawa D, Barcikowski M, Palme R (2017) Parent-offspring interactions in a long-lived seabird, the little auk (Alle alle): begging and provisioning under simulated stress. J Ornithol 158:145-157. https://doi. org/10.1007/s10336-016-1382-y

Kidawa D, Jakubas D, Wojczulanis-Jakubas K, Iliszko L, Stempniewicz L (2012) The effects of loggers on the foraging effort and chickrearing ability of parent little auks. Polar Biol 35:909-917. https:// doi.org/10.1007/s00300-011-1136-5

Kidawa D, Jakubas D, Wojczulanis-Jakubas K, Stempniewicz L, Trudnowska E, Boehnke R, Schonberger L, Błachowiak-Samołyk K (2015) Parental efforts of an Arctic seabird, the little auk Alle alle under variable foraging conditions. Mar Biol Res 11:349-360. https://doi.org/10.1080/17451000.2014.940974 
Korpimäki E, Salo P, Valkama J (2011) Sequential polyandry by brood desertion increases female fitness in a bird with obligatory biparental care. Behav Ecol Sociobiol 65:1093-1102. https://doi.org/ 10.1007/s00265-010-1118-6

Kwasniewski S, Gluchowska M, Jakubas D, Wojczulanis-Jakubas K, Walkusz W, Karnovsky NJ, Błachowiak-Samołyk K, Cisek M, Stempniewicz L (2010) The impact of different hydrographic conditions and zooplankton communities on provisioning little auks along the west coast of Spitsbergen. Prog Oceanogr 87:72-82. https://doi.org/10.1016/j.pocean.2010.06.004

Moe B, Stempniewicz L, Jakubas D, Angelier F, Chastel O, Dinessen F, Gabrielsen GW, Hanssen F, Karnovsky NJ, Rønning B, Welcker J, Wojczulanis-Jakubas K, Bech C (2009) Climate change and phenological responses of two seabird species breeding in the high-Arctic. Mar Ecol Prog Ser 393:235-246. https://doi.org/10.3354/ meps08222

Morton ES, Stutchbury BJM, Chiver I (2010) Parental conflict and brood desertion by females in blue-headed vireos. Behav Ecol Sociobiol 64:947-954. https://doi.org/10.1007/s00265-010-0910-7

Orians GH (2011) On the evolution of mating systems in birds and mammals. Am Nat 103:589-603

Piechura J, Walczowski W (2009) Warming of the West Spitsbergen current and sea ice north of Svalbard. Oceanologia 51:147-164. https://doi.org/10.5697/oc.51-2.147

Pierce EP (1997) Sex roles in the monogamous purple sandpiper Calidris maritima. Ibis 139:159-169

Pilastro A, Biddau L, Marin G, Mingozzi T (2001) Female brood desertion increases with number of available mates in the rock sparrow. J Avian Biol 32:68-72. https://doi.org/10.1034/j.1600-048X.2001. 320109.x

Promińska A, Cisek M, Walczowski W (2017) Kongsfjorden and Hornsund hydrography - comparative study based on a multiyear survey in fjords of West Spitsbergen. Oceanologia 59:397-412. https://doi.org/10.1016/j.oceano.2017.07.003

R Core Team (2018) R: a language and environment for statistical computing. R foundation for statistical computing. Vienna, Austria. http://www.R-project.org

Roskaft E (2006) The effect of enlarged brood size on the future reproductive potential of the rook. J Anim Ecol 54:255-260. https://doi. org/10.2307/4635

Rossmanith E, Blaum N, Höntsch K, Jeltsch F (2009) Sex-related parental care strategies in the lesser spotted woodpecker Picoides minor: of flexible mothers and dependable fathers. J Avian Biol 40:28-33. https://doi.org/10.1111/j.1600-048X.2008.04353.x

Steen H, Vogedes D, Broms F, Falk-Petersen S, Berge J (2007) Little auks (Alle alle) breeding in a high Arctic fjord system: bimodal foraging strategies as a response to poor food quality? Polar Res 26:118-125. https://doi.org/10.1111/j.1751-8369.2007.00022.x

Stempniewicz L (2001) Little auk (Alle alle). BWP Update 3:175-201

Szekely T, Cuthill IC (2000) Trade-off between mating opportunities and parental care: brood desertion by female Kentish plovers. Proc R Soc Lond B 267:2087-2092. https://doi.org/10.1098/rspb.2000. 1253

Székely T, Williams TD (1995) Costs and benefits of brood desertion in female Kentish plovers, Charadrius alexandrinus. Behav Ecol Sociobiol 37:155-161. https://doi.org/10.1007/BF00176712

Therneau TM, Lumley T (2019) Package ' survival '. Survival Analysis, https: / /CRAN.R-project.org/package=survival

Trivers R (1972) Parental investment and sexual selection. In: Campbell B (ed) Sexual selection and the descent of man. Aldine, Chicago, pp 136-179
Tuomo MS, Harald S (2001) Across the Arctic front west of Spitsbergen: high-resolution CTD sections from 1998-2000. Polar Res 20:177184

Walczowski W, Piechura J (2007) Pathways of the Greenland Sea warming. Geophys Res Lett 34:1-5. https://doi.org/10.1029/ 2007GL029974

Webb JN, Székely T, Houston AI, McNamara JM (2002) A theoretical analysis of the energetic costs and consequences of parental care decisions. Phil Trans R Soc B 357:331-340. https://doi.org/10. 1098/rstb.2001.0934

Welcker J, Harding AMA, Karnovsky NJ, Steen H, Strom H, Gabrielsen NJ (2009a) Flexibility in the bimodal foraging strategy of a high Arctic alcid, the little auk Alle alle. J Avian Biol 40:388-399. https://doi.org/10.1111/j.1600-048X.2008.04620.x

Welcker J, Steen H, Harding AMA, Gabrielsen GW (2009b) Sex-specific provisioning behaviour in a monomorphic seabird with a bimodal foraging strategy. Ibis 151:502-513. https://doi.org/10.1111/j.1474919X.2009.00931.X

Wickham H, Chang W, Henry L, Pedersen TL, Takahashi K, Wilke C, Woo K, Yutani H, Dunnington D (2018) Package"ggplot2". Create elegant data visualisations using the grammar of graphics description, http://ggplot2.tidyverse.org

Wojczulanis-Jakubas K, Araya-Salas M, Jakubas D (2018) Seabird parents provision their chick in a coordinated manner. PLoS One 13: e0189969. https://doi.org/10.1371/journal.pone.0189969

Wojczulanis-Jakubas K, Jakubas D (2012) When and why does my mother leave me? The question of brood desertion in the dovekie (Alle alle). Auk 129:632-637. https://doi.org/10.1525/auk.2012. 12095

Wojczulanis-Jakubas K, Jakubas D, Chastel O (2014a) Different tactics, one goal: initial reproductive investments of males and females in a small Arctic seabird. Behav Ecol Sociobiol 68:1521-1530. https:// doi.org/10.1007/s00265-014-1761-4

Wojczulanis-Jakubas K, Jakubas D, Chastel O, Kulaszewicz I (2015) A big storm in a small body: seasonal changes in body mass, hormone concentrations and leukocyte profile in the little auk (Alle alle). Polar Biol 38:1203-1212. https://doi.org/10.1007/s00300-015-1687-y

Wojczulanis-Jakubas K, Jakubas D, Karnovsky NJ, Walkusz W (2010) Foraging strategy of little auks under divergent conditions on feeding grounds. Polar Res 29:22-29. https://doi.org/10.1111/j.17518369.2009.00145.x

Wojczulanis-Jakubas K, Jakubas D, Kidawa D, Kośmicka A (2012) Is the transition from biparental to male-only care in a monogamous seabird related to changes in body mass and stress level? J Ornithol 153: 793-800. https://doi.org/10.1007/s10336-011-0796-9

Wojczulanis-Jakubas K, Jakubas D, Kulaszewicz I, Kidawa D, Taylor JRE (2014b) Influence of primary reproductive investments on blood biochemistry, leukocyte profile, and body mass in a small Arctic seabird. Auk 131:743-755. https://doi.org/10.1642/AUK$14-62.1$

Wojczulanis-Jakubas K, Jakubas D, Stempniewicz L (2009) Sex-specific parental care by incubating little auks (Alle alle). Ornis Fenn 86: $140-148$

Zuur AF, Leno EN, Walker NJ, Saveliev AA, Smith GM (2009) Mixed effects models and extensions in ecology with R. Springer Verlag, New York

Publisher's note Springer Nature remains neutral with regard to jurisdictional claims in published maps and institutional affiliations. 